\title{
Not so 'rare'-an example of malignant melanoma in India: report from a tertiary cancer centre
}

\author{
Bivas Biswas ${ }^{1}$, Gautam Biswas ${ }^{2}$, Sandip Ganguly ${ }^{1}$, Joydeep Ghosh ${ }^{1}$, Somnath Roy ${ }^{1}$, Manas Kumar Roy ${ }^{3}$, Amrit Pipara ${ }^{3}$, Jagriti Karmakar ${ }^{1}$, \\ Navonil Mukherjee ${ }^{1}$, Santam Chakraborty ${ }^{4}$, Deepak Kumar Mishra ${ }^{5}$, Divya Midha ${ }^{6}$ and Deepak Dabkara ${ }^{1}$ \\ ${ }^{1}$ Department of Medical Oncology, Tata Medical Center, 14 MAR [EW], New Town, Rajarhat, Kolkata 700160, West Bengal, India \\ ${ }^{2}$ Department of Plastic \& Reconstructive Surgery, Tata Medical Center, 14 MAR [EW], New Town, Rajarhat, Kolkata 700160, West Bengal, India \\ ${ }^{3}$ Department of GI Surgery, Tata Medical Center, 14 MAR [EW], New Town, Rajarhat, Kolkata 700160, West Bengal, India \\ ${ }^{4}$ Department of Radiotherapy, Tata Medical Center, 14 MAR [EW], New Town, Rajarhat, Kolkata 700160, West Bengal, India \\ ${ }^{5}$ Department of Molecular Oncology, Tata Medical Center, 14 MAR [EW], New Town, Rajarhat, Kolkata 700160, West Bengal, India \\ ${ }^{6}$ Department of Pathology, Tata Medical Center, 14 MAR [EW], New Town, Rajarhat, Kolkata 700160, West Bengal, India
}

\begin{abstract}
Purpose: Malignant melanoma (MM) is rare in India. Indian data on demography and treatment outcome on advanced MM is very limited in the literature.

Materials \& methods: This is a retrospective study of advanced MM treated between January 2013 and December 2020. We evaluated the clinicopathologic features, mutational profiles, survival outcome and prognostic factors in advanced MM patients.

Results: Out of a total 460 patients, 185 (42\%) had metastatic disease at presentation and were enrolled in this study with a median age of 63 years (range: 28-93) and male:female ratio of $94: 91$. The mucosal primary was predominant $(n=110,59 \%)$ than cutaneous primary (38\%) and anorectum was the most common site $(n=84,45 \%)$. Tumour mutational analysis was performed in $65(35 \%)$ patients. BRAF mutations were detected in 12 patients and KIT mutations in 7 patients. Thirteen patients didn't have any mutations and 22 patients had mutations other than KIT \& BRAF. Only 59 (32\%) patients took any systemic treatment - immune checkpoint inhibitors (ICls) in 17, temozolomide in 18 and paclitaxel/carboplatin in 18, tyrosine kinase inhibitors in 6 patients. After a median follow-up of 26 months (95\% confidence interval (Cl): 11.6-not reached), median progression-free survival (PFS) was 7.1 months (95\% Cl: 4.4-9.1) and median overall survival was 14.8 months (95\% Cl: 7.7-18.2 months). The use of ICl emerged as an only significant good prognostic factor $(p \leq 0.001)$ for PFS, on multivariate analysis.
\end{abstract}

Conclusion: Mucosal origin was more common than cutaneous primary with anorectum being the most common site. BRAF mutation was less as compared to published literature. Very few patients received systemic therapy and the use of $\mathrm{ICl}$ showed superior PFS.

Keywords: BRAF, melanoma, India, anorectum
Correspondence to: Bivas Biswas

Email: bivasbiswas@gmail.com

ecancer 2021, 15:1335

https://doi.org/10.3332/ecancer.2021.1335

Published: $16 / 12 / 2021$

Received: 03/07/2021

Publication costs for this article were supported by ecancer (UK Charity number 1176307).

Copyright: ( ) the authors; licensee ecancermedicalscience. This is an Open Access article distributed under the terms of the Creative Commons Attribution License (http:// creativecommons.org/licenses/by/4.0), which permits unrestricted use, distribution, and reproduction in any medium, provided the original work is properly cited. 


\section{Introduction}

Malignant melanoma (MM) is an aggressive cutaneous malignancy and ranked 17th in incidence amongst all malignancies globally with a reported annual incidence of 324,635 cases as per Global Cancer Observatory (GLOBOCAN) 2020 data [1]. The incidence of cutaneous melanoma is increasing globally with an estimated 5-year related survival of 93.3\% [2]. MM ranked 32nd spot in India as per yearly incidence and recorded 3,916 cases (0.3\% of all cases) as per GLOBOCAN 2020 data [3].

Melanocyte exists outside the skin too and can give rise to non-cutaneous MM arising from mucus membrane, uveal tract and leptomeninges [4]. Mucosal MM most often arises from head and neck sinuses and oral cavity, anorectum, vulva and vagina, any other site of the gastrointestinal tract or urogenital tract [5] and constitutes less than $5 \%$ of all melanoma cases [6]. The majority of cutaneous MM in western countries presents in the early localised stage (84\%) and only $4 \%$ presents with advanced stage of disease [7]. The genetic profile of MM varies according to sites and with chronic sun exposure. BRAF mutation was highest in patients with MM without chronic sun exposure (56\%) whereas KIT aberration was mostly found in those of acral, mucosal MM and those with chronic sun exposure (28\%-39\%) [8].

The survival outcomes of advanced MM have dramatically improved with the discovery of novel targeted therapies like BRAF tyrosine kinase inhibitors (TKIs) (like - vemurafenib, dabrafenib) [9, 10] and immune checkpoint inhibitors (ICls) (nivolumab, pembrolizumab, ipilimumab) [11-13] and established as the standard of care. In comparison, cytotoxic chemotherapy with dacarbazine (DTIC), temozolomide (TMZ) [14] or paclitaxel/carboplatin [15] has shown only a modest and short-lasting response rate.

There is no large-scale publication from India [16-20] about demography, molecular pattern, treatment pattern and/or outcome of MM, and neither any registration trial of novel targeted therapies or immunotherapies has included Indian patients. Here, we have analysed the demography, clinicopathologic feature, tumour mutational profile, treatment pattern including those with novel therapies and outcome of metastatic MM patients treated at our institute.

\section{Materials \& methods}

\section{Patients}

This is a retrospective chart review study of all patients $\geq 18$ years of age with histologically proven diagnosis of MM treated between January 2013 and December 2020 at our institute. Patients with distant organ metastasis or extensive in-transit metastasis (not amenable for surgical resection) were enrolled for demographic details, clinicopathologic features, treatment details and outcome. A waiver was received from Institutional Review Board because of the retrospective nature of the study.

\section{Diagnosis}

All patients had trucut biopsy or fine-needle aspiration cytology with cell block and demonstration of melanin pigment with appropriate immunohistochemistry (S100, HMB 45 and Melan-A). Spindle cell melanoma (which is mostly amelanotic) was diagnosed with morphology and appropriate immunohistochemistry as mentioned. All patients underwent ${ }^{18}$ Fluorodeoxyglucose positron emission tomography coupled with computed tomography (CT) or contrast-enhanced CT scan of thorax \& whole abdomen at baseline. ${ }^{99}$ Technicium bone scan was performed in case of bone related symptoms or elevated serum alkaline phosphatase (in absence of liver metastasis). Central nervous system imaging (either CT scan or magnetic resonance imaging) was performed in symptomatic patients. Baseline lactate dehydrogenase (LDH) was measured for prognostication and as a follow-up tumour marker. Appropriate organ function was measured in those receiving systemic therapy.

\section{Molecular diagnostics}

Every effort was made to perform KIT and BRAF mutation in all eligible patients. In-house molecular testing started at the end of 2017. BRAF mutation was tested by next-generation sequencing (NGS) using lon Torrent platform with cancer hotspot V2 panel. KIT mutation was tested in all patients with mucosal melanoma by NGS. BRAF mutation was not performed in patients who don't have access to anti-BRAF TKI. 


\section{Treatment and response}

Patients were offered systemic chemotherapy or immunotherapy (preferred option) wherever applicable. Cytotoxic chemotherapy included oral TMZ, inj. DTIC, paclitaxel (conventional or albumin-bound or nanoparticle) with carboplatin. Nivolumab (3 mg/kg every 2 weeks) and pembrolizumab (200 mg every 3 weeks) are approved in India in patients with advanced melanoma. A similar treatment profile was extrapolated for patients with mucosal melanoma. Dabrafenib (150 mg twice daily in empty stomach) \& trametinib ( 2 mg once daily in empty stomach) are the only TKI combination approved in India for advanced melanoma with BRAF v600E/K mutation and the same was recommended for patients with BRAF v600E/K mutation and a few patients with BRAF v600R/D mutation. Appropriate imaging was performed at 2nd or 3rd month of treatment for first response assessment and thereafter as needed or indicated and response measured as complete response (CR), partial response (PR), stable disease (SD) or progressive disease (PD) as per Response Evaluation Criteria in Solid Tumors (RECIST) criteria [21].

\section{Statistical analysis}

Descriptive statistics were used for demographics and clinical characteristics. A Chi-square test was used to detect an association between categorical variables. The student's $t$-test was applied to compare continuous variables between groups. Survival analysis was performed only in patients who received any form of systemic anti-cancer therapy. Survival was estimated by the Kaplan-Meier method and compared using a log-rank test. Data were censored on 30 April 2021. The Cox proportional hazard model was used in univariate analysis to detect outcome differences between groups. Stepwise multivariate Cox regression analysis was done to identify the predictors of outcome. Factors with significance $(p \leq 0.1)$ in the univariate analysis were entered into multivariate analysis. Progression-free survival (PFS) with the standard error was calculated from the date of starting treatment to the date of disease progression or death due to any cause. Overall survival (OS) with the standard error was calculated from the date of diagnosis to the date of death from any cause. Patients who were lost to follow-up or had treatment abandonment were also included for PFS and OS analysis and the outcome in these patients was confirmed by telephonic contact. Treatment abandonment was included for survival analysis in the present study as it has been proposed that non-compliant and treatment abandonment patients should be included in survival analysis for studies from developing nations to provide a true picture of outcomes from these countries [22]. STATA/SE 11.0 (StataCorp LP, Texas) was used for statistical analysis.

\section{Results}

\section{Clinicopathologic features}

Out of total 460 patients, 185 patients had metastatic disease and were enrolled in this study with a median age of 63 years (range: 28-93; interquartile range: 53-71) and male:female ratio of 94:91. Clinicopathologic characteristics are mentioned in Table 1. The mucosal primary was predominant $(n=110,59 \%)$ than cutaneous primary (38\%) and anorectum was the most common site $(n=84,45 \%)$. Most common sites of metastasis were distant lymph nodes ( $n=78,42 \%$ ) followed by lung ( $n=67,36 \%$ ) and liver ( $n=66$, 36\%). More than two sites of organ metastasis were present in 37 (20\%) patients. The majority of patients didn't have baseline LDH and hence were not considered for analysis as a prognostic factor for outcome analysis.

\section{Tumour mutational profile}

Tumour mutational analysis was performed in 65 (35\%) patients. NGS was performed in 45 patients, KIT and BRAF sequencing was performed in 5 patients and only c-KIT sequencing was done in 15 patients (Table 1). The mutational profile is depicted in Figure 1 and Table 2. Ten patients had BRAF mutation ( $20 \%, n=50$ ) in v600 codon (v600E in 6 , v600R in 3 and v600K in 1 patient) and two had non-v600 codon (N581I and S605I). The KIT mutation was present in seven (11\%) patients as follows - exon 10 in one, exon 11 in two, exon 13 in two, exon 15 in one and exon 17 in one patient. Thirteen $(29 \%, n=45)$ patients didn't have any mutations in NGS testing. Amongst the mucosal 
melanoma, 34 underwent mutational testing and 4 patients had BRAF mutations ( 3 had v600 codon mutation and 1 non-v600 codon mutation) and another 4 had KIT mutations. Twenty-two (49\%) patients had mutations other than KIT \& BRAF which include NRAS mutations in five patients (11\%).

Table 1. Baseline clinicopathologic features.

\begin{tabular}{|c|c|}
\hline Variables & Number (\%) \\
\hline Age in years (median; range) & $63 ; 28-93$ \\
\hline \multicolumn{2}{|l|}{ Gender } \\
\hline Male & $94(51)$ \\
\hline Female & $91(49)$ \\
\hline Symptom duration in months (median; range) & $5 ; 0.3-60$ \\
\hline \multicolumn{2}{|l|}{ ECOG PS } \\
\hline PS 1 & $132(71)$ \\
\hline PS 2 & $36(20)$ \\
\hline PS 3 & $10(5)$ \\
\hline PS 4 & $7(4)$ \\
\hline \multicolumn{2}{|l|}{ Type of disease } \\
\hline Cutaneous & $71(38)$ \\
\hline Mucosal & $110(59)$ \\
\hline Uveal + spinal meninges & $4(3)$ \\
\hline \multicolumn{2}{|l|}{ Site of disease } \\
\hline Extremity & $56(30)$ \\
\hline Head \& neck & $22(12)$ \\
\hline Anorectum & $84(45)$ \\
\hline Uro-genitals & $11(6)$ \\
\hline Others & $12(7)$ \\
\hline \multicolumn{2}{|l|}{ Site of metastasis } \\
\hline Distant lymph node & $78(42)$ \\
\hline Lung & $67(36)$ \\
\hline Liver & $66(36)$ \\
\hline Skin \& soft tissue & $62(34)$ \\
\hline Bone & $31(16)$ \\
\hline Brain $^{a}$ & 17 \\
\hline \multicolumn{2}{|l|}{ Molecular analysis $(n=65)$} \\
\hline NGS & 45 \\
\hline KIT \& BRAF sequencing & 5 \\
\hline KIT sequencing only & 15 \\
\hline \multicolumn{2}{|l|}{ Mutation $(n=65)$} \\
\hline BRAF & 12 \\
\hline KIT & 7 \\
\hline Others & 22 \\
\hline No mutation & 13 \\
\hline
\end{tabular}

ECOG, Eastern Cooperative Oncology Group

${ }^{a}$ Brain imaging performed only in symptomatic cases 


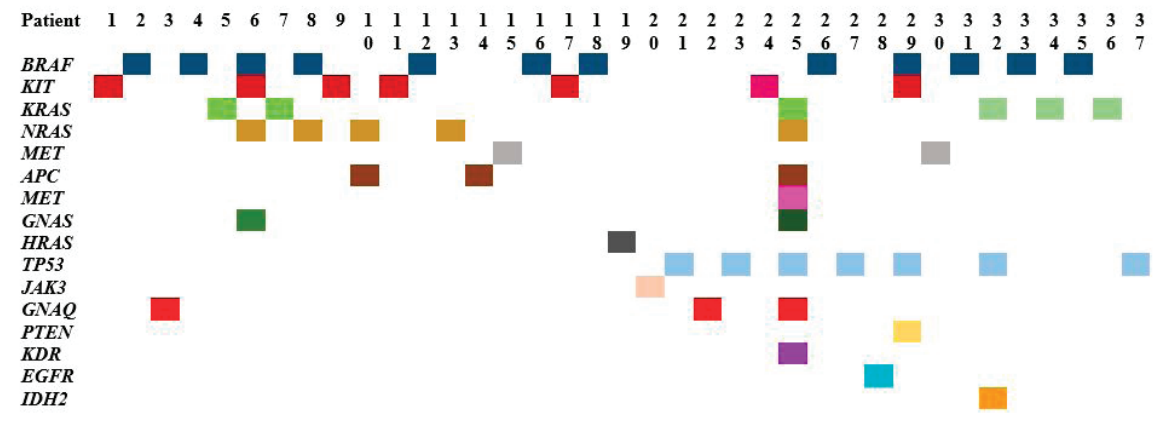

Figure 1. NGS tumour mutational profile of 37 patients with at least one mutation present $(n=37)$.

Table 2. NGS tumour mutational profile of 37 patients with at least one mutation present $(n=37)$.

\begin{tabular}{|c|c|c|}
\hline Mutational profile & Number & $\%$ \\
\hline$B R A F$ & 9 & $24 \%$ \\
\hline$B R A F+N R A S$ & 1 & $2.5 \%$ \\
\hline$B R A F+K I T+N R A S+G N A S$ & 1 & $2.5 \%$ \\
\hline$B R A F+K I T+T P 53+P T E N$ & 1 & $2.5 \%$ \\
\hline KIT & 4 & $11 \% 1$ \\
\hline KRAS & 4 & $11 \%$ \\
\hline$K R A S+N R A S+A P C+G N A S+T P 53+G N A Q+K R D$ & 1 & $2.5 \%$ \\
\hline$K R A S+T P 53+I D H 2$ & 1 & $2.5 \%$ \\
\hline NRAS & 2 & $5 \%$ \\
\hline$N R A S+A P C$ & 1 & $2.5 \%$ \\
\hline MET & 2 & $5 \%$ \\
\hline$A P C$ & 2 & $5 \%$ \\
\hline GNAS & 1 & $2.5 \%$ \\
\hline HRAS & 1 & $2.5 \%$ \\
\hline TP53 & 4 & $11 \%$ \\
\hline GNAQ & 2 & $5 \%$ \\
\hline EGFR & 1 & $2.5 \%$ \\
\hline
\end{tabular}

\section{Treatment \& response}

Only 59 (32\%) patients took any systemic treatment for their advanced-stage disease (Table 3). Seventeen patients received ICls as follows nivolumab in eight patients \& pembrolizumab in nine patients. Response to ICI $(n=16)$ was $C R$ in one, PR in seven, SD in five and PD in three patients. Eighteen patients received oral TMZ based therapy and another 18 patients received platinum and taxane combination. Response to chemotherapy was - CR in 1, PR in 3, SD in 15, PD in 15 and status not known in 2 patients. In second line setting, four patients received dabrafenib/trametinib combination therapy (all with BRAF v600 mutation) and two patients received nivolumab. Response to dabrafenib/ 
trametinib combination therapy (two in first line setting and four in second line setting) was CR in one, PR in three, SD in one and PD in one patient. Three patients received imatinib as upfront therapy for c-kit mutation and two achieved PRs (exon 11 \& exon 13 - one each) and the third patient had clinically PD (exon 13). For brain metastasis, ten patients received whole-brain radiotherapy, two patients underwent surgical resection of the brain lesion and one patient defaulted before any treatment.

\section{Survival outcome}

After a median follow-up of 26 months (95\% confidence interval (CI): 11.6-not reached), the median PFS was 6.1 months (95\% Cl: 4.4-9.1) (Figure 2a) and median OS was 14.8 months (95\% Cl: 7.7-18.2 months) (Figure 2b). The PFS with dabrafenib \& trametinib was 6 months \& 8 months in first line use and 2, 3, 9, 20 months, respectively, for second line use. The PFS with imatinib was $2,13.2 \& 28.5$ months, respectively, for three patients. The median PFS \& median OS with first line ICl was 17.6 ( $95 \%$ Cl: 5.13 -not reached) months and 21.7 months ( $95 \%$ Cl: 6.9-42.9), respectively.

\section{Univariate \& multivariate analysis}

The univariate analysis of PFS and OS is mentioned in Table 4. Type of systemic therapy $(p \leq 0.001)$ emerged as only significant for PFS (Figure 2c) whereas none of the factors predicted OS.

Table 3. Systemic therapy treatment details.

\begin{tabular}{|c|c|}
\hline Agents & Number \\
\hline \multicolumn{2}{|l|}{ First line setting $(n=59)$} \\
\hline Pembrolizumab & 9 \\
\hline Nivolumab & 8 \\
\hline TMZ & 18 \\
\hline Paclitaxel/carboplatin & 14 \\
\hline Nab-paclitaxel/carboplatin & 4 \\
\hline Imatinib & 3 \\
\hline Dabrafenib/trametinib & 2 \\
\hline Crizotinib & 1 \\
\hline \multicolumn{2}{|l|}{ Second line setting $(n=17)$} \\
\hline Nivolumab & 2 \\
\hline Dabrafenib/trametinib & 4 \\
\hline Temozolomide & 4 \\
\hline Paclitaxel/carboplatin & 5 \\
\hline Nab-paclitaxel/carboplatin & 1 \\
\hline Sunitinib & 1 \\
\hline
\end{tabular}



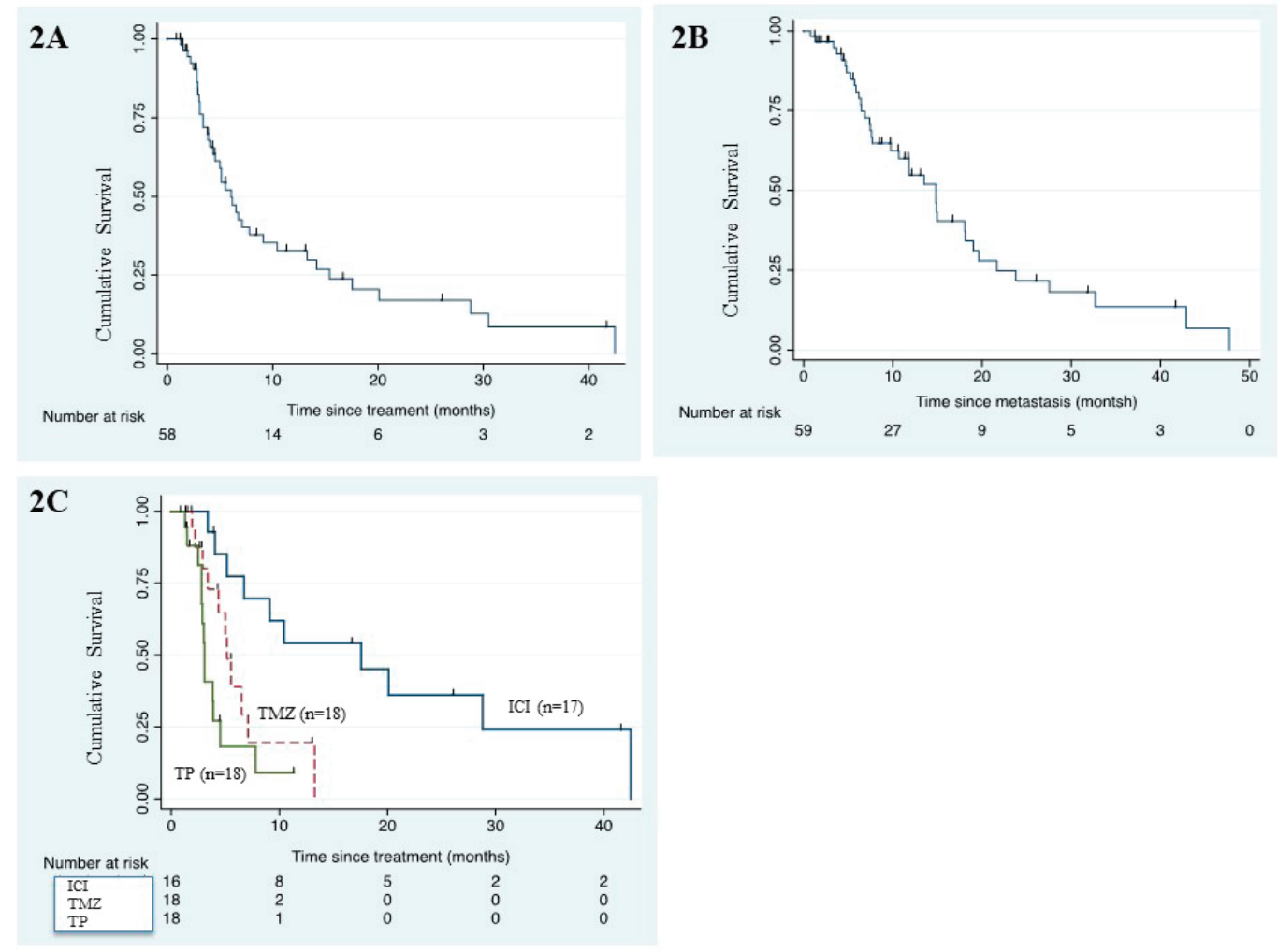

Figure 2. (a): Kaplan-Meier curve for PFS in the whole cohort $(n=59)$. (b): Kaplan-Meier survival curve for OS of the whole cohort ( $n=59)$. (c): KaplanMeier PFS curve according to type of systemic therapy. (ICl, immune checkpoint inhibitor; TMZ, temozolomide; TP, paclitaxel/carboplatin)

\section{Discussion}

MM is rare in India [3] and there are few studies on MM regarding its epidemiology, clinicopathologic features, molecular spectrum and treatment outcome due to its rarity. It constitutes $2 \%$ of all newly diagnosed solid tumours (460 out of 23,300 cases during the study period) in our hospital as compared to $0.3 \%$ cases in India as per GLOBOCAN 2020 data [3]. In our cohort, 185 patients with metastatic disease had predominantly mucosal melanoma, $20 \%$ had BRAF mutation, 11\% KIT mutation and only one-third took any systemic treatment with a median PFS of 9 months, and one-third of them took an ICl agent. The median age in our cohort was 63 years which was similar to western data [2].

One hundred and ten (59\%) patients had mucosal melanoma in our cohort which is a very high incidence as compared to western literature [5] and the majority of the mucosal melanoma was anorectal origin (76\%). Both of these observations can be due to the referral bias at our institute being a tertiary care oncology institute. We don't have any in-house ophthalmic oncology service and this fact may represent very few uveal melanomas in our cohort. It may be a fact that mucosal melanoma incidence is high in India and possibly in the Indian subcontinent as evident by other Indian studies [16, 19, 20]. The high incidence of metastatic disease (185 out of 460) may due to a higher incidence of mucosal melanoma which is very aggressive and presents late, due to delayed referral owing to not much familiarity of the disease entity amongst primary care physicians, etc. 
Table 4. Univariate analysis for PFS \& OS ( $n=59)$.

\begin{tabular}{|c|c|c|c|c|c|c|c|}
\hline \multirow[b]{2}{*}{ Variables } & \multirow[b]{2}{*}{ Category (n) } & \multicolumn{3}{|c|}{ PFS } & \multicolumn{3}{|c|}{ OS } \\
\hline & & HR & $\mathrm{Cl}$ & $p$ & HR & $\mathrm{Cl}$ & $p$ \\
\hline \multirow[t]{2}{*}{ Age (years) } & $\leq 60(n=31)$ & 1 & & 0.11 & 1 & & 0.63 \\
\hline & $>60(n=28)$ & 0.59 & $0.3-1.13$ & & 0.85 & $0.44-1.65$ & \\
\hline \multirow[t]{2}{*}{ Gender } & Male $(n=32)$ & 1 & & 0.87 & 1 & & 0.86 \\
\hline & Female $(n=27)$ & 1.05 & $0.55-2.01$ & & 1.06 & $0.54-2.06$ & \\
\hline \multirow{2}{*}{$\begin{array}{l}\text { Symptoms } \\
\text { durations }\end{array}$} & $\leq 4$ months $(n=30)$ & 1 & & 0.16 & 1 & & 0.26 \\
\hline & $>4$ months $(n=29)$ & 0.63 & $0.33-1.2$ & & 0.68 & $0.34-1.11$ & \\
\hline \multirow[t]{2}{*}{ ECOG PS } & PS 1 ( $n=39)$ & 1 & & 0.6 & 1 & & 0.82 \\
\hline & $P S \geq 2(n=20)$ & 0.84 & $0.43-1.62$ & & 0.92 & $0.47-1.82$ & \\
\hline \multirow{2}{*}{$\begin{array}{l}\text { Type of } \\
\text { disease }\end{array}$} & Cutaneous $(n=20)$ & 1 & & 0.16 & 1 & & 0.06 \\
\hline & Mucosal/visceral $(n=39)$ & 1.64 & $0.82-3.26$ & & 2.02 & $0.97-4.23$ & \\
\hline \multirow{2}{*}{$\begin{array}{l}\text { Metastatic } \\
\text { sites }\end{array}$} & $<3$ sites $(n=148)$ & 1 & & 0.45 & 1 & & 0.45 \\
\hline & $\geq 3$ sites $(n=37)$ & 1.33 & $0.64-2.75$ & & 1.36 & $0.61-3.04$ & \\
\hline \multirow{3}{*}{$\begin{array}{l}\text { Treatment } \\
\text { types }^{\mathrm{a}}\end{array}$} & $\mathrm{ICI}(n=17)$ & 1 & & $<0.001$ & 1 & & 0.06 \\
\hline & $\mathrm{TMZ}(n=18)$ & 3.3 & $1.19-9.2$ & & 1.32 & $0.49-3.55$ & \\
\hline & $\operatorname{TP}(n=18)$ & 6.58 & $2.36-18.4$ & & 2.21 & $0.95-5.12$ & \\
\hline
\end{tabular}

$\mathrm{Cl}$, Confidence interval; ECOG, Eastern Cooperative Oncology Group; HR, Hazard ratio; ICl, Immune check point inhibitor; PS, Performance status; TMZ, Temozolomide; TP, Paclitaxel/carboplatin

asix patients received other systemic therapies

BRAF mutation was detected in $20 \%$ of the tested population which was much lower as compared to published international data of as high as $56 \%$ [8]. This finding may be due to the low sample size as not all patients underwent BRAF testing and secondly, a very high incidence of mucosal melanoma in our cohort where the incidence of BRAF mutation is very low. KIT aberration (mutation) was present in $11 \%$ of the tested population and again very low incidence in mucosal melanoma (4 out of 34 tested). Three patients had BRAF v600R mutation and two had a long-term response (PFS of 9 months and 20 months, respectively) to dabrafenib/trametinib combination therapy in second line setting (after cytotoxic chemotherapy failure) similar to published literature [23-25].

Only one-third patients $(n=59)$ received systemic therapy owing to many factors - many patients present in very late-stage disease with poor performance status (PS) ( $n=53,30 \%$ in our cohort), many patients can't afford immunotherapy (only 16 patients received ICl in first line setting), BRAF inhibitor was not available in India during the study period (all received the drug through compassionate access), many didn't opt for cytotoxic chemotherapy because of dismal outcome (median PFS of 5.1 months and 3.1 months with TMZ and paclitaxel/carboplatin, respectively) and many patients did came for second opinion at our centre after initial treatment elsewhere. Compliance with treatment and access to care is one of the big issues owing to the aforementioned factors in MM patients as we have experienced in our study. Only two $[16,20]$ of the five Indian studies have reported treatment outcomes (Table 5) in abstract form only and that too mostly with cytotoxic chemotherapy similar to our study results. There is very limited access to clinical trials for MM in India owing to the rarity of the disease in this part of the world.

High serum LDH and $\geq 3$ sites of metastatic disease are well established poor prognostic factors for PFS and OS in advanced/metastatic MM $[26,27]$. Mucosal variety has a poor prognosis as compared to cutaneous variety. We didn't have LDH in the majority of our patients. Metastatic sites or mucosal origin didn't show any prognostic significance in our series owing to a small number of patients who received systemic therapy. $\mathrm{ICl}$ use outperformed other cytotoxic chemotherapy. 
Table 5. Published Indian data on advanced MM.

\begin{tabular}{|c|c|c|c|c|c|c|c|c|}
\hline Author (period) & $N$ & Site/type & $\begin{array}{l}\text { Molecular } \\
\text { features }\end{array}$ & Chemotherapy & Immunotherapy & $\begin{array}{l}\text { Targeted } \\
\text { therapy }\end{array}$ & $\begin{array}{l}\text { Median } \\
\text { PFS }\end{array}$ & $\begin{array}{l}\text { Median } \\
\text { OS }\end{array}$ \\
\hline $\begin{array}{l}\text { Panda et al [18] } \\
(2011-2016)\end{array}$ & $\begin{array}{l}182 \\
\text { Metastatic - } \\
47 \%\end{array}$ & $\begin{array}{l}\text { Skin - 93\% } \\
\text { Mucosa - 7\% }\end{array}$ & NR & NR & NR & NR & NR & NR \\
\hline $\begin{array}{l}\text { Sharma et al [19] } \\
(1995-2007)\end{array}$ & $\begin{array}{l}72 \\
\text { Metastatic - } \\
12 \%\end{array}$ & $\begin{array}{l}\text { Skin - 35\% } \\
\text { Mucosa - 25\% } \\
\text { Viscera - } 40 \%\end{array}$ & NR & $\begin{array}{l}N=10 \\
\text { Multiple agents }\end{array}$ & NR & NR & 10 months $^{\mathrm{a}}$ & NR \\
\hline $\begin{array}{l}\text { Mukhopadhyay } \\
\text { et al [17] } \\
(2016-2019)\end{array}$ & $\begin{array}{l}93 \\
\text { Metastatic - } \\
86 \%\end{array}$ & $\begin{array}{l}\text { Skin }-48 \% \\
\text { Mucosa - 52\% }\end{array}$ & Not performed & $\begin{array}{l}N=39 \\
\text { DTIC - } 27 \\
\text { Nab-pacli - } 6 \\
\text { Others - } 6\end{array}$ & $\begin{array}{l}N=16 \text { (all } \\
\text { nivolumab) }\end{array}$ & None & 3 months & NR \\
\hline $\begin{array}{l}\text { Subhalakshmi } \\
(2000-2005)\end{array}$ & $\begin{array}{l}16 \\
\text { Metastatic } \\
-6 \%\end{array}$ & $\begin{array}{l}\text { Skin - 79\% } \\
\text { Mucosa - 11\% }\end{array}$ & NR & NR & NR & NR & NR & NR \\
\hline $\begin{array}{l}\text { Agarwal }^{b} \text { et al [16] } \\
(2013-2019)\end{array}$ & $\begin{array}{l}443 \\
\text { Metastatic - } \\
42 \%\end{array}$ & $\begin{array}{l}\text { Skin }-41 \% \\
\text { Mucosa - 57\% }\end{array}$ & BRAF - 11\% & $\begin{array}{l}N=138 \text { (DTIC, taxane, } \\
\text { interferon) }\end{array}$ & $N=29$ & None & 5.5 months & $\begin{array}{l}11 \\
\text { months }\end{array}$ \\
\hline $\begin{array}{l}\text { Current study } \\
(2013-2020)\end{array}$ & $\begin{array}{l}460 \\
\text { Metastatic - } \\
185(40 \%)\end{array}$ & $\begin{array}{l}\text { Skin - 38\% } \\
\text { Mucosal - } \\
59 \%\end{array}$ & $\begin{array}{l}\text { BRAF - } 20 \% \\
\text { KIT - } 11 \% \\
\text { Others - } 49 \%\end{array}$ & $\begin{array}{l}\text { TMZ - } 18 \\
\text { Taxane } / \text { carbo = } 18\end{array}$ & $N=17$ & $N=10^{c}$ & 7.1 months & $\begin{array}{l}14.8 \\
\text { months }\end{array}$ \\
\hline
\end{tabular}

DTIC, Dacarbazine; NR, Not reported; OS, Overall survival; PFS, Progression free survival; TMZ, Temozolomide

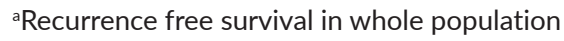

${ }^{\mathrm{b}}$ Abstract only

'Six patients received dabrafenib/trametinib, three received imatinib and one received crizotinib (in all lines of therapy)

There are many limitations in our study. Only one-third of patients took any systemic treatment and many patients lost to follow-up after progression on first line treatment. Hence, prognostication is very difficult with this small sample size. We didn't have the value of LDH in most of our patients, which is a very important prognostic factor in advanced MM. Our study cohort had referral bias with mucosal primary as the major portion of the population, less head-neck primary but more anorectal primary, very rare cases of uveal melanoma, etc.

\section{Conclusion}

To conclude, melanoma is not that rare in India as reported in GLOBOCAN 2020 database. The majority of our patients had mucosal primary than the cutaneous origin with a very high incidence of metastasis at presentation. Ano-rectal mucosal primary has the maximum incidence probably due to referral bias. Very few patients took systemic treatment and the outcome was determined by the use of ICl over cytotoxic chemotherapy. Access to modern systemic therapy (TKI and ICI) is 'the' major concern for the treatment of advanced MM in India owing to the very high cost of the TKI and ICl. Increasing awareness among the primary physician, timely referral to an oncology centre, increasing awareness amongst patients about the disease, multidisciplinary management and improved access to modern systemic therapy may improve current management \& outcome of advanced MM in India. 


\section{Acknowledgments}

The authors would like to be thankful to all patients \& their caregivers for giving them the opportunity, and the entire resident doctors, nursing and support staff in the institute.

\section{Ethical clearance}

Institute Ethics Committee Protocol Waiver No-EC/WV/TMC/16/21.

\section{Conflicts of interest}

None for each author.

\section{Funding}

Nil.

\section{Authors' contributions}

Concept and design: BB, SG, SR, DD, SC, AP, DM

Data entry, analysis: BB, SR, JK, NM, JG, DKM, MKR

Manuscript writing, proofreading, final approval: All authors

This study has not been presented in any conference or symposia or elsewhere.

\section{References}

1. IARC Global Cancer Observatory [Internet] (Lyon: IARC) [https://gco.iarc.fr/] Date accessed: $3 / 06 / 21$

2. National Cancer Institute Melanoma of the Skin - Cancer Stat Facts [Internet] [https://seer.cancer.gov/statfacts/html/melan.html] Date accessed: $3 / 06 / 21$

3. https://gco.iarc.fr/today/data/factsheets/populations/356-india-fact-sheets.pdf

4. Kibbi N, Kluger H, and Choi JN (2016) Melanoma: clinical presentations Cancer Treat Res 167 107-129 https://doi.org/10.1007/978-3319-22539-5_4

5. Mihajlovic M, Vlajkovic S, and Jovanovic P, et al (2012) Primary mucosal melanomas: a comprehensive review Int J Clin Exp Pathol 5(8) 739-753 PMID: 23071856 PMCID: 3466987

6. Postow MA, Hamid O, and Carvajal RD (2012) Mucosal melanoma: pathogenesis, clinical behavior, and management Curr Oncol Rep 14(5) 441-448 https://doi.org/10.1007/s11912-012-0244-x PMID: 22661391

7. Siegel RL, Miller KD, and Jemal A (2015) Cancer statistics, 2015 CA Cancer J Clin 65(1) 5-29 https://doi.org/10.3322/caac.21254 PMID: 25559415

8. Curtin JA, Busam K, and Pinkel D, et al (2006) Somatic activation of KIT in distinct subtypes of melanoma J Clin Oncol Off J Am Soc Clin Oncol 24(26) 4340-4346 https://doi.org/10.1200/JCO.2006.06.2984 
9. Larkin J, Ascierto PA, and Dréno B, et al (2014) Combined vemurafenib and cobimetinib in BRAF-mutated melanoma N Engl J Med 371(20) 1867-1876 https://doi.org/10.1056/NEJMoa1408868 PMID: 25265494

10. Long GV, Stroyakovskiy D, and Gogas H, et al (2015) Dabrafenib and trametinib versus dabrafenib and placebo for Val600 BRAFmutant melanoma: a multicentre, double-blind, phase 3 randomised controlled trial Lancet Lond Engl 386(9992) 444-451 https://doi. org/10.1016/S0140-6736(15)60898-4

11. Larkin J, Chiarion-Sileni V, and Gonzalez R, et al (2015) Combined nivolumab and ipilimumab or monotherapy in untreated melanoma N Engl J Med 373(1) 23-34 https://doi.org/10.1056/NEJMoa1504030 PMID: 26027431 PMCID: 5698905

12. Larkin J, Minor D, and D'Angelo S, et al (2018) Overall survival in patients with advanced melanoma who received nivolumab versus investigator's choice chemotherapy in check mate 037: a randomized, controlled, open-label phase III trial J Clin Oncol Off J Am Soc Clin Oncol 36(4) 383-390 https://doi.org/10.1200/JCO.2016.71.8023

13. Robert C, Schachter J, and Long GV, et al (2015) Pembrolizumab versus ipilimumab in advanced melanoma N Engl J Med 372(26) 25212532 https://doi.org/10.1056/NEJMoa1503093 PMID: 25891173

14. Middleton MR, Grob JJ, and Aaronson N, et al (2000) Randomized phase III study of temozolomide versus dacarbazine in the treatment of patients with advanced metastatic malignant melanoma J Clin Oncol Off J Am Soc Clin Oncol 18(1) 158-166 https://doi.org/10.1200/ JCO.2000.18.1.158

15. Hauschild A, Agarwala SS, and Trefzer U, et al (2009) Results of a phase III, randomized, placebo-controlled study of sorafenib in combination with carboplatin and paclitaxel as second-line treatment in patients with unresectable stage III or stage IV melanoma J Clin Oncol Off J Am Soc Clin Oncol 27(17) 2823-2830 https://doi.org/10.1200/JCO.2007.15.7636

16. Agarwal A, Bajpai J, and Chatterjee A, et al (2020) 429P demographics, pattern of care, and outcome analysis of malignant melanoma cases from a tertiary care centre in India Ann Oncol 31 S1410 [https://www.annalsofoncology.org/article/S0923-7534(20)42912-6/ abstract] Date accessed: 25/04/21 https://doi.org/10.1016/j.annonc.2020.10.421

17. Mukhopadhyay S, Ghosh S, and Siddhartha D, et al (2008) A clinicopathological study of malignant melanoma with special reference to atypical presentation Indian J Pathol Microbiol 51(4) 485-488 https://doi.org/10.4103/0377-4929.43736 PMID: 19008571

18. Panda S, Dash S, and Besra K, et al (2018) Clinicopathological study of malignant melanoma in a regional cancer center Indian J Cancer 55(3) 292-296 https://doi.org/10.4103/ijc.IJC_612_17

19. Sharma K, Mohanti BK, and Rath GK (2009) Malignant melanoma: a retrospective series from a regional cancer center in India J Cancer Res Ther 5(3) 173-180 https://doi.org/10.4103/0973-1482.57122 PMID: 19841558

20. Shishak SA, Rastogi S, and Pandey R, et al (2019) Malignant melanoma: a study of clinical profiles and treatment outcomes in Indian patients Ann Oncol 30 ix117 [https://www.annalsofoncology.org/article/S0923-7534(19)57996-0/abstract] Date accessed: 25/04/21 https://doi.org/10.1093/annonc/mdz429.007

21. Eisenhauer EA, Therasse P, and Bogaerts J, et al (2009) New response evaluation criteria in solid tumours: revised RECIST guideline (version 1.1) Eur J Cancer 45(2) 228-247 https://doi.org/10.1016/j.ejca.2008.10.026

22. Mostert S, Arora RS, and Arreola M, et al (2011) Abandonment of treatment for childhood cancer: position statement of a SIOP PODC Working Group Lancet Oncol 12(8) 719-720 https://doi.org/10.1016/S1470-2045(11)70128-0 PMID: 21719348

23. Klein O, Clements A, and Menzies AM, et al (2013) BRAF inhibitor activity in V600R metastatic melanoma Eur J Cancer 49(5) 10731079 https://doi.org/10.1016/j.ejca.2012.11.004

24. Casadevall D, Vidal J, and Gallardo F, et al (2016) Dabrafenib in an elderly patient with metastatic melanoma and BRAF V600R mutation: a case report J Med Case Reports 10(1) 158 Date accessed: 07/06/21 https://doi.org/10.1186/s13256-016-0953-0 
25. Menzer C, Menzies AM, and Carlino MS, et al (2019) Targeted therapy in advanced melanoma with rare BRAF mutations J Clin Oncol 37(33) 3142-3151 Date accessed: 07/06/21 https://doi.org/10.1200/JCO.19.00489 PMID: 31580757

26. Long GV, Stroyakovskiy D, and Gogas H, et al (2015) Dabrafenib and trametinib versus dabrafenib and placebo for Val600 BRAFmutant melanoma: a multicentre, double-blind, phase 3 randomised controlled trial Lancet Lond Engl 386(9992) 444-451 https://doi. org/10.1016/S0140-6736(15)60898-4

27. Weide B, Elsässer M, and Büttner P, et al (2012) Serum markers lactate dehydrogenase and S100B predict independently disease outcome in melanoma patients with distant metastasis Br J Cancer 107(3) 422-428 https://doi.org/10.1038/bjc.2012.306 PMID: 22782342 PMCID: $\underline{3405231}$ 